\title{
A Selective Synthesis of TaON Nanoparticles and Their Comparative Study of Photoelectrochemical Properties
}

\author{
Vijay Khanal ${ }^{1}$, Eric Soto-Harrison ${ }^{1}$, Dhanesh Chandra ${ }^{1}$, Narmina O. Balayeva ${ }^{2}$, \\ Detlef W. Bahnemann 2,3,4 (D) and Vaidyanathan (Ravi) Subramanian 1,2,4,* \\ 1 Chemical and Materials Engineering, University of Nevada, Reno, NV 89557, USA; \\ vj.khanal20@gmail.com (V.K.); compumaster123@gmail.com (E.S.-H.); dchandra@unr.edu (D.C.) \\ 2 Institute of Technical Chemistry, Gottfried Wilhelm Leibniz University of Hannover, Callinstr. 5, \\ D-30167 Hannover, Germany; balayeva@iftc.uni-hannover.de (N.O.B.); \\ bahnemann@iftc.uni-hannover.de (D.W.B.) \\ 3 Laboratory “Photoactive Nanocomposite Materials”, Saint-Petersburg State University, Ulyanovskaya str.1, \\ Peterhof, 198504 Saint-Petersburg, Russia \\ 4 Laboratory of Nano and Quantum Engineering Gottfried Wilhelm Leibniz University of Hannover, \\ Schneiderberg 39, D-30167 Hannover, Germany \\ * Correspondence: ravisv@unr.edu
}

Received: 21 August 2020; Accepted: 23 September 2020; Published: 1 October 2020

check for updates

\begin{abstract}
A simplified ammonolysis method for synthesizing single phase TaON nanoparticles is presented and the resulting photoelectrochemical properties are compared and contrasted with as-synthesized $\mathrm{Ta}_{2} \mathrm{O}_{5}$ and $\mathrm{Ta}_{3} \mathrm{~N}_{5}$. The protocol for partial nitridation of $\mathrm{Ta}_{2} \mathrm{O}_{5}$ (synthesis of TaON) offers a straightforward simplification over existing methods. Moreover, the present protocol offers extreme reproducibility and enhanced chemical safety. The morphological characterization of the as-synthesized photocatalysts indicate spherical nanoparticles with sizes 30, 40, and $30 \mathrm{~nm}$ $\mathrm{Ta}_{2} \mathrm{O}_{5}, \mathrm{TaON}$, and $\mathrm{Ta}_{3} \mathrm{~N}_{5}$ with the absorbance onset at $\sim 320 \mathrm{~nm}, 580 \mathrm{~nm}$, and $630 \mathrm{~nm}$ respectively. The photoactivity of the catalysts has been examined for the degradation of a representative cationic dye methylene blue $(\mathrm{MB})$ using xenon light. Subsequent nitridation of $\mathrm{Ta}_{2} \mathrm{O}_{5}$ yields significant increment in the conversion $\left(\zeta: \mathrm{Ta}_{2} \mathrm{O}_{5}<\mathrm{TaON}<\mathrm{Ta}_{3} \mathrm{~N}_{5}\right.$ ) mainly attributable to the defect-facilitated adsorption of $\mathrm{MB}$ on the catalyst surface and bandgap lowering of catalysts with $\mathrm{Ta}_{3} \mathrm{~N}_{5}$ showing $>95 \% \zeta$ for a lower (0.1 g) loading and with a lamp with lower Ultraviolet (UV) content. Improved Photoelectrochemical performance is noted after a series of chronoamperometry $(\mathrm{J} / \mathrm{t})$, linear sweep voltammetry (LSV), and electrochemical impedance spectroscopy (EIS) measurements. Finally, stability experiments performed using recovered and treated photocatalyst show no loss of photoactivity, suggesting the photocatalysts can be successfully recycled.
\end{abstract}

Keywords: $\mathrm{Ta}_{2} \mathrm{O}_{5}$; $\mathrm{TaON} ; \mathrm{Ta}_{3} \mathrm{~N}_{5}$; methylene blue; photocatalysis; photoelectrochemistry

\section{Introduction}

Large and small bandgap single metal oxides have traditionally been the class of materials relied upon to assist with photocatalytic environmental remediation [1]. They are typically used (i) as standalone photocatalysts, (ii) with variations in physical dimensions, (iii) with other additives to form heterostructured junctions for enhancing photoactivity [2]. Several studies have indicated that the last of the three approaches is the most effective. Some of the popular strategies included in this approach is using the single metal oxides with co-catalysts such as metals [3], with carbon as additive [4], or with other oxides [5], to either increase optical absorbance or enhance charge separation or both. Such a single metal oxide photocatalyst or their composites have proven their viability in both gas and liquid phase environmental pollutant remediation. The leading examples of single metal oxide photocatalysts 
are $\mathrm{TiO}_{2}$ or $\mathrm{ZnO}$ and their combinations with metals [6], an additional (different) oxide [7]. These additives primarily aid in improving photoactivity.

The tantalum-based oxides are less studied although they demonstrate optical and electronic responses, just like $\mathrm{TiO}_{2}$ and $\mathrm{ZnO}[8,9]$. A leading cause for the limited activity of the tantalum oxide is its inherently large bandgap of $3.9 \mathrm{eV}$ which makes it photoactive only in the far left of the ultraviolet (UV) compared to the popular $\mathrm{TiO}_{2}$. Besides, tantalum is a more expensive source compared to titanium or zinc. However, as evident from recent research, tantalum-based oxides continue to demonstrate multifunctionality making them worthy of consideration for a systematic investigation [9-12]. Tantalum oxide has a bandgap that straddles the redox potential of water making it a viable candidate, if properly optimized to absorb visible light, that would facilitate production of solar fuels [13]. For example, they can be integrated with the most earth abundant and eco-friendly element-nitrogen-to form oxynitrides: $\mathrm{TaO}_{\mathrm{x}} \mathrm{N}_{\mathrm{y}}(\mathrm{y}=1-\mathrm{x})[14,15]$. This singular option allows for tuning the optical bandgap $\left(\mathrm{E}_{\mathrm{g}}\right)$ over a wide range of 1.6-4.0 eV solely based on Ta: $\mathrm{O}: \mathrm{N}$ ratio. Such phases are reported to enhance visible light absorbance with $\mathrm{O}: \mathrm{N}$ ratio dependent bandgap tunability as shown in Scheme 1. These customizable oxidation potential levels can aid in tuning photo-driven processes triggered using broad spectrum visible absorption. tantalum-based oxides and oxynitrides also demonstrate compatibility with inorganic (metal and other semiconductors) and organic additives [16,17].

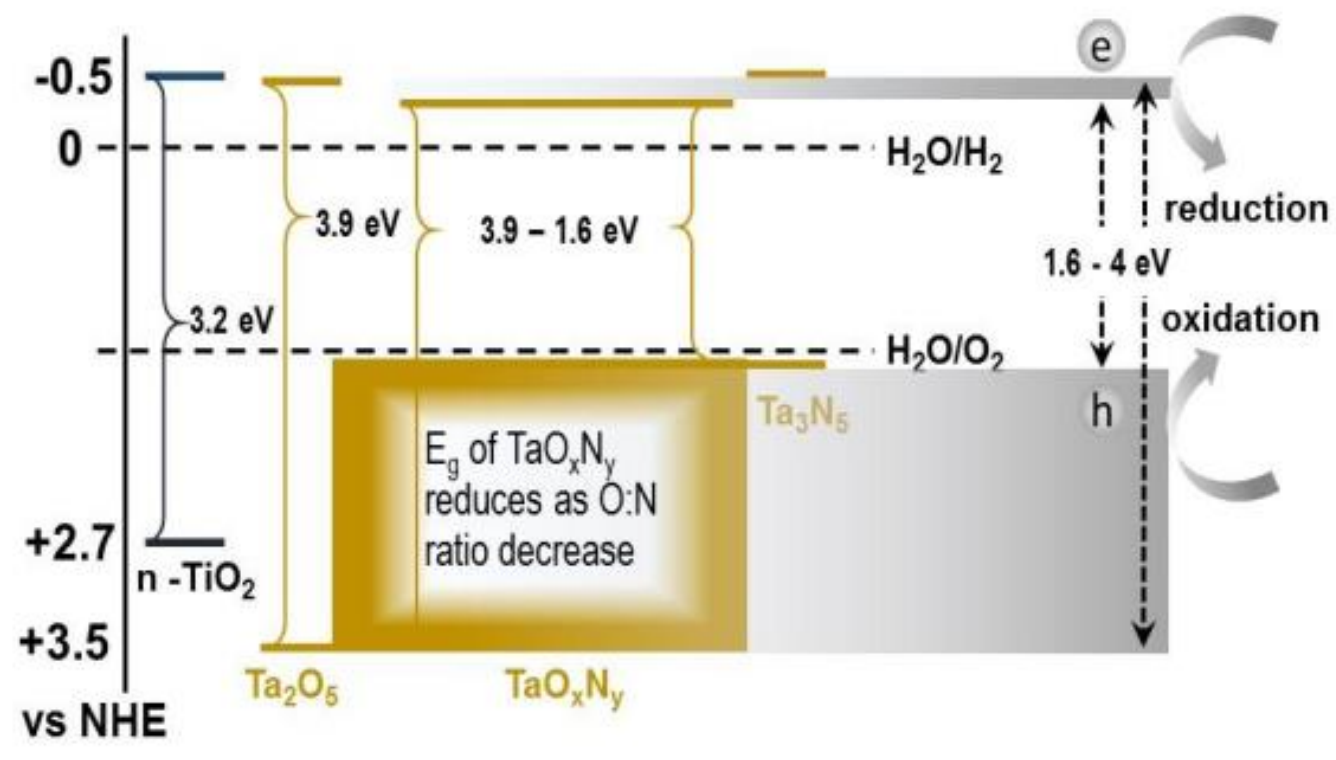

Scheme 1. The bandedge positions of the tantalum-based oxides, oxynitriles $\left(\mathrm{TaO}_{x} \mathrm{~N}_{y}\right)$, and nitride $\left(\mathrm{Ta}_{3} \mathrm{~N}_{5}\right)$ relative to the popular $\mathrm{TiO}_{2}$. As indicated, tantalum-based oxides are amenable to bandgap (Eg) change via tuning the valence band edge by varying $\mathrm{O}: \mathrm{N}$ ratio to influence photoactivity.

The synthesis and application of tantalum-based oxides, oxynitrides, and their composites have been reported previously in the literature. The catalysts reported here are compared to similar Ta-based catalysts reported elsewhere [18-21]. One of the prominent applications of pure $\mathrm{Ta}_{2} \mathrm{O}_{5}$ [22] and doped (with alkali) $\mathrm{Ta}_{2} \mathrm{O}_{5}$ [23] is towards water decomposition/hydrogen evolution [24-26]. Environmental applications such as photocatalytic oxidation of dyes have also been observed [20,27-29]. Following complete nitridation of the $\mathrm{Ta}_{2} \mathrm{O}_{5}$ results in the formation of $\mathrm{Ta}_{3} \mathrm{~N}_{5}$, which has been reported to aid with water oxidation/oxygen evolution [13,26,30-32]. Further, from a greenhouse gas mitigation standpoint, $\mathrm{Ta}_{2} \mathrm{O}_{5}$ is also reported to aid with $\mathrm{CO}_{2}$ reduction [33]. Like other oxides, the photoactivity of tantalum-based oxides is critically influenced by the method used to synthesize them including the additives used in the synthesis and the shape they may evolve [34,35].

This work presents partial and complete nitridation of $\mathrm{Ta}_{2} \mathrm{O}_{5}$ using two different approaches. The approach to partial nitridation of $\mathrm{Ta}_{2} \mathrm{O}_{5}$ reported herein is first of its kind is a simple one that 
guarantees synthesis of a single phase of $\mathrm{TaON}$. A comparison of the $\mathrm{Ta}_{2} \mathrm{O}_{5}, \mathrm{TaON}$, and $\mathrm{Ta}_{3} \mathrm{~N}_{5}$ activity as photocatalysts for the remediation of a representative environmental pollutant methylene blue (MB) is discussed and compared. The practical viability of TaON is tested by recycling the catalyst multiple times and the results of photoelectrochemical measurements are used to obtain mechanistic insights into the improved performance by the in-house catalysts.

\section{Results}

\subsection{Characterization of the Photocatalyst}

\subsubsection{Analysis of Nanoparticle Morphology Using Scanning Electron Microscopy (SEM)}

The physical features of the commercial and the in-house synthesized samples were examined using the SEM. The commercial samples (Figure S2) are non-spherical with large nanoparticle clusters, with some as big as $300 \mathrm{~nm}$. For the most part these clusters tend to be $\sim 100 \mathrm{~nm}$ average diameter. In comparison, the in-house oxide samples are more spherical, with an order of magnitude smaller diameter clusters of 20-30 nm. Further, the size distribution among the in-house nanoparticles is narrow and well controlled, as shown in Figure 1a. The SEM image of the sample obtained after partial and complete nitridation is shown in Figure $1 b, c$ respectively. The nitridation process slightly alters the physical morphology of the clusters, notably introducing the atomic defects. It is to be noted that such defects contribute to the adsorption of pollutant molecules and electron-paramagnetic resonance (EPR) studies are suggested for further exploration of the nature of such defects [36]. The post nitridation particle sizes for the partially and completely nitrided samples is observed to be $\sim 40-50 \mathrm{~nm}$ (Figure 1b) and $\sim 30-40 \mathrm{~nm}$ (Figure 1c) respectively. To understand further if these clusters contain smaller particles, a transmission electron microscopy (TEM) analysis was performed. TEM analysis is important because a smaller size of the in-house synthesized samples can indicate the availability of more surface, which is consistent with a surfactant-assisted method used for synthesis. It is also important to mention that the availability of more surface is a pre-requisite for ensuring better contact between the photocatalyst and the pollutant molecules leading to enhancement in the dye adsorption and facilitate interfacial redox processes such as catalysis.
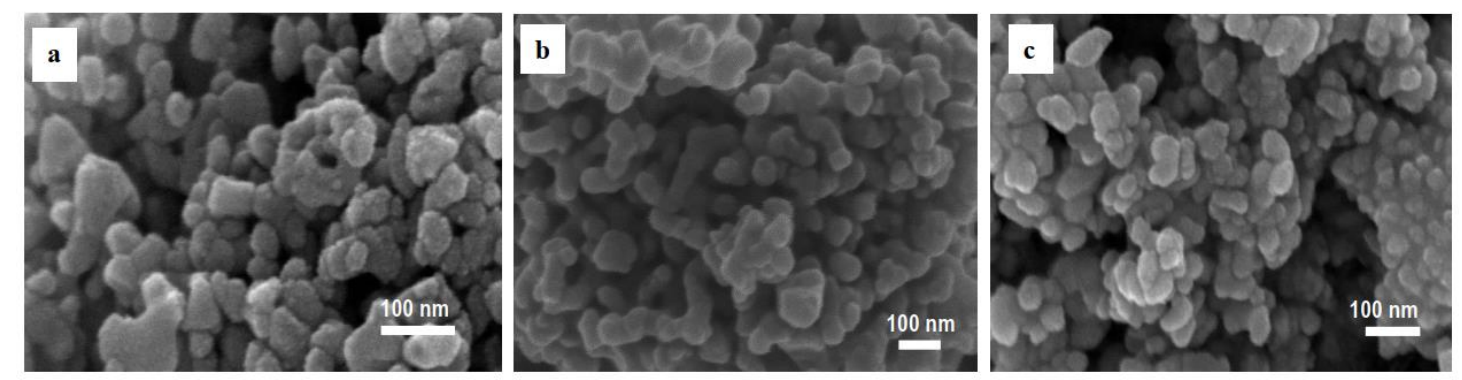

Figure 1. The scanning electron microscope (SEM) image of the (a) as-synthesized oxide from Ta-precursor after annealing in air, (b) partial nitridation of the annealed oxide, and (c) complete nitridation of the oxide. Inherent crystal-defects developed during each synthesis step are noted to add on the altered morphology of the catalyst samples.

\subsubsection{HRTEM Analysis of the Photocatalysts Samples before and after Nitridation}

The High Resolution Transmission Electron Microscopy (HRTEM) analysis of the in-house synthesized thermally annealed samples before and after nitridation is shown in Figure 2. The particle sizes of the thermally annealed samples in the air (Figure 2a) are $\sim 6-7 \mathrm{~nm}$. The particle sizes of the partially annealed samples in humidified $\mathrm{NH}_{4} \mathrm{OH}$ vapor (Figure $2 \mathrm{~b}$ ) are $\sim 10 \mathrm{~nm}$. Finally, the samples prepared by treatment in dry $\mathrm{NH}_{3}$ are larger at $\sim 20-30 \mathrm{~nm}$. The high-resolution images of all the samples show distinct evidence of crystallinity after annealing. These images indicate that the annealing leads to crystallization, as observed with other oxides [37]. The figures also show the 
respective selected area electron diffraction (SAED) pattern of the samples. The presence of the geometric diffraction pattern confirms thermally induced crystallization. The characteristic $d$-spacings are marked in the image and suggest that the samples shown in Figure $2 \mathrm{a}-\mathrm{c}$ are respectively $\mathrm{Ta}_{2} \mathrm{O}_{5}$, $\mathrm{TaON}$, and $\mathrm{Ta}_{3} \mathrm{~N}_{5}$. Brunauer-Emmett-Teller (BET) specific surface areas $\left(\mathrm{S}_{\mathrm{BET}}\right.$ ) analysis was performed using $\mathrm{N}_{2}$ physisorption and the surface area was estimated to be $1.6 \mathrm{~m}^{2} / \mathrm{g}$ for commercial $\mathrm{Ta}_{2} \mathrm{O}_{5}$, $41.08 \mathrm{~m}^{2} / \mathrm{g}$ for $\mathrm{Ta}_{2} \mathrm{O}_{5}$ (in-house), and $17.44 \mathrm{~m}^{2} / \mathrm{g}$ for the $\mathrm{Ta}_{3} \mathrm{~N}_{5}$.

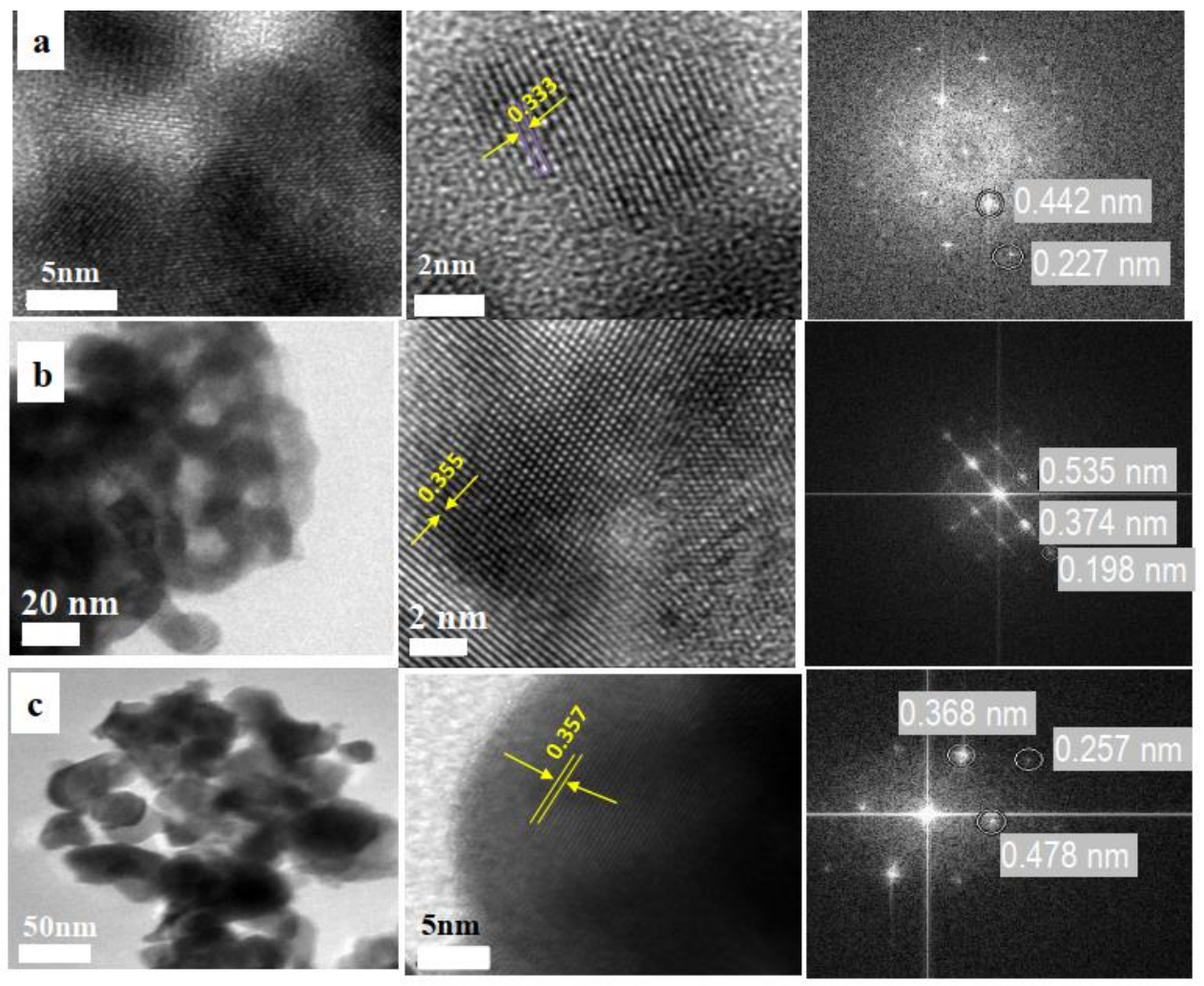

Figure 2. The figure shows the HRTEM images of the in-house synthesized thermally annealed samples (a) before nitridation, and (b) after partial nitridation $\left(\mathrm{NH}_{4} \mathrm{OH}\right)$ and (c) after complete nitridation (dry $\mathrm{NH}_{3}$ ). From left to right the images in (a-c) also indicate the characteristic d-spacing, and the SAED pattern confirming that the nanoparticles are crystalline $\mathrm{Ta}_{2} \mathrm{O}_{5}, \mathrm{TaON}$, and $\mathrm{Ta}_{3} \mathrm{~N}_{5}$ respectively.

\subsubsection{Phase Identification Using X-ray Diffraction (XRD)}

The phase of the oxide and the nitride samples was determined using XRD analysis. The in-house un-annealed sample did not show any distinguishable Bragg peaks indicating that they are amorphous. However, post thermal treatment, the in-house synthesized samples showed distinct Bragg peaks (Figure 3a) indicating that annealing transforms the amorphous samples to polycrystalline aggregates. These characteristic peaks in both samples matched with the standard JCPDS (Joint Committee on Powder Diffraction Systems) database. The commercial and in-house samples indicated a match with file \# 00-018-1304 identifying as $\mathrm{Ta}_{2} \mathrm{O}_{5}$. The XRD of the sample after partial nitridation is shown in Figure $3 \mathrm{~b}$ and is identified as TaON (JCPDS \# 01-071-0178 40). Miller indices as identified in the XRD patterns of the newly synthesized single phase TaON also are shown. The XRD pattern of the fully reduced phase of $\mathrm{Ta}_{2} \mathrm{O}_{5}-\mathrm{Ta}_{3} \mathrm{~N}_{5}$ obtained after conventional high temperature dry ammonia treatment can be indexed to the $\mathrm{Ta}_{3} \mathrm{~N}_{5}$ phase (JCPDS \# 00-019-1291) as shown in Figure 3c. The formation of crystalline phases is an essential pre-requisite to any photocatalytic activity $[38,39]$. Scherer analysis was performed by applying the expression: crystallite size $=\frac{0.9 \lambda}{\beta \cos \theta}$, where $\beta$ is the full width at half maximum (FWHM) of characteristic peaks in the sample, $\theta$ is the Bragg angle. The particle sizes estimated for $\mathrm{Ta}_{2} \mathrm{O}_{5}, \mathrm{TaON}$, and $\mathrm{Ta}_{3} \mathrm{~N}_{5}$ were $\sim 26 \mathrm{~nm}, 27 \mathrm{~nm}$, and $29 \mathrm{~nm}$, respectively. 


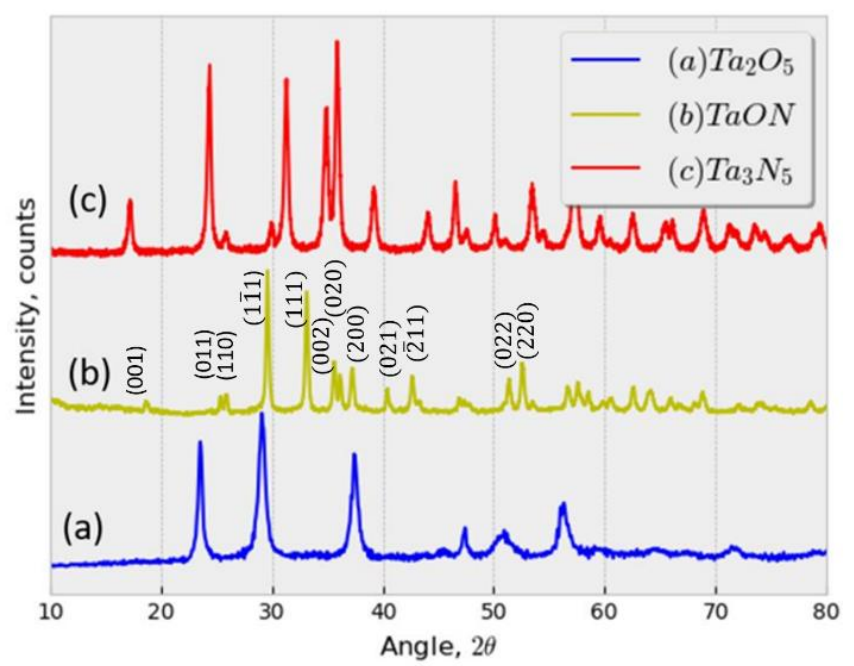

Figure 3. X-Ray diffractograms of the as-synthesized (a) $\mathrm{Ta}_{2} \mathrm{O}_{5}$ (JCPDS \# 00-018-1304), (b) TaON (JCPDS \# 01-071-0178 40), and (c) $\mathrm{Ta}_{3} \mathrm{~N}_{5}$ (JCPDS \# 00-019-1291).

\subsubsection{Optical Analysis Using Spectroscopy}

The absorbance spectra of the $\mathrm{Ta}_{2} \mathrm{O}_{5}$ and the $\mathrm{Ta}_{3} \mathrm{~N}_{5}$ prepared as films on Indium-Tin-Oxide (ITO) coated glass are shown in Figure 4 and the inset shows pictures of the powder of the three samples. The $\mathrm{Ta}_{2} \mathrm{O}_{5}$ is white (the onset absorbance of the in-house sample extrapolates to $320 \mathrm{~nm}$ ). Both TaON and $\mathrm{Ta}_{3} \mathrm{~N}_{5}$ are colored and this coloration is indicative of the incorporation of nitrogen. $\mathrm{The} \mathrm{Ta}_{2} \mathrm{O}_{5}$ has a bandgap in the range of 3.6-3.9 eV and the onset noted in this range is consistent with the observations reported on oxides synthesized using wet chemical approaches [40]. This onset is also evidence that photoactivity is driven predominantly by UV light. Unlike $\mathrm{Ta}_{2} \mathrm{O}_{5}$, the $\mathrm{TaON}$ and $\mathrm{Ta}_{3} \mathrm{~N}_{5}$ show a significant red shift into the visible region. The absorbance of $\mathrm{TaON}(\sim 580 \mathrm{~nm})$ and $\mathrm{Ta}_{3} \mathrm{~N}_{5}$ $(\sim 630 \mathrm{~nm})$ are indicative of smaller bandgaps. The experimental determination of the bandgap was performed using the Tauc plot analysis [41,42]. A bandgap of $3.66 \mathrm{eV}, 2.1 \mathrm{eV}$ and $1.71 \mathrm{eV}$ for $\mathrm{Ta}_{2} \mathrm{O}_{5}$, $\mathrm{TaON}$, and $\mathrm{Ta}_{3} \mathrm{~N}_{5}$, respectively was estimated from this analysis as indicated in the inset of Figure 4.

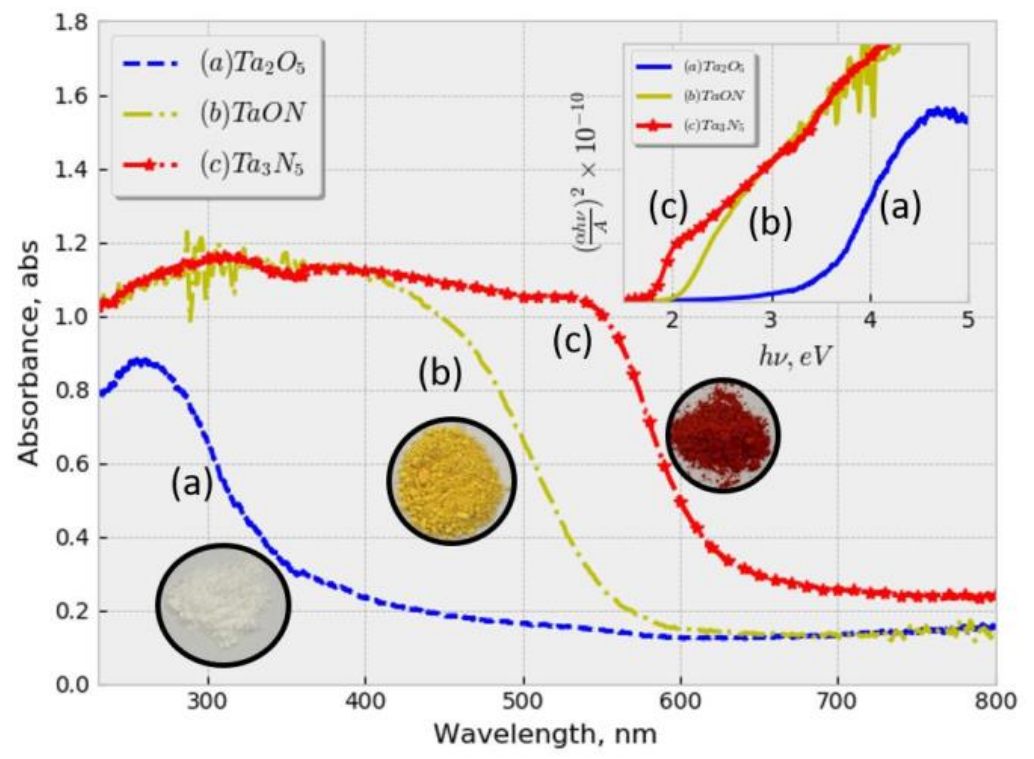

Figure 4. The absorbance spectra of the (a) as-synthesized $\mathrm{Ta}_{2} \mathrm{O}_{5},(\mathbf{b}) \mathrm{TaON}$, and (c) $\mathrm{Ta}_{3} \mathrm{~N}_{5}$. As indicated in the photographs of the samples, the coloration, shown alongside, conforms to the corresponding absorbance spectra. Tauc's plots for bandgap ( $\mathrm{E}_{\mathrm{g}}$ ) estimation are shown in the inset. $\mathrm{E}_{\mathrm{g}}$ for $\mathrm{Ta}_{2} \mathrm{O}_{5}, \mathrm{TaON}$, and $\mathrm{Ta}_{3} \mathrm{~N}_{5}$ were estimated to be $3.66,2.21$, and $1.71 \mathrm{eV}$ respectively. (This figure is best viewed in color). 


\subsection{Evaluation of the Photocatalytic Activity towards Methylene Blue Degradation}

\subsubsection{Methylene Blue Absorbance and Photolytic Conversion}

Methylene blue (MB) is a multi-purpose organic colored dye and a representative model pollutant whose photodegradation is of immense interest $[43,44]$. The optical spectra of a pure aqueous MB solution demonstrate visible light absorbance with a starting characteristic peak absorbance at $670 \mathrm{~nm}[45,46]$. Therefore, its degradation can be probed using spectrometry by tracking the change at $670 \mathrm{~nm}$. Figure 5 a shows the representative dye absorbance before illumination and the effects of photoillumination using UV-vis light. The dye demonstrates notable photolytic conversion with the Xe lamp as the excitation source. The conversion observed was $25 \%$.
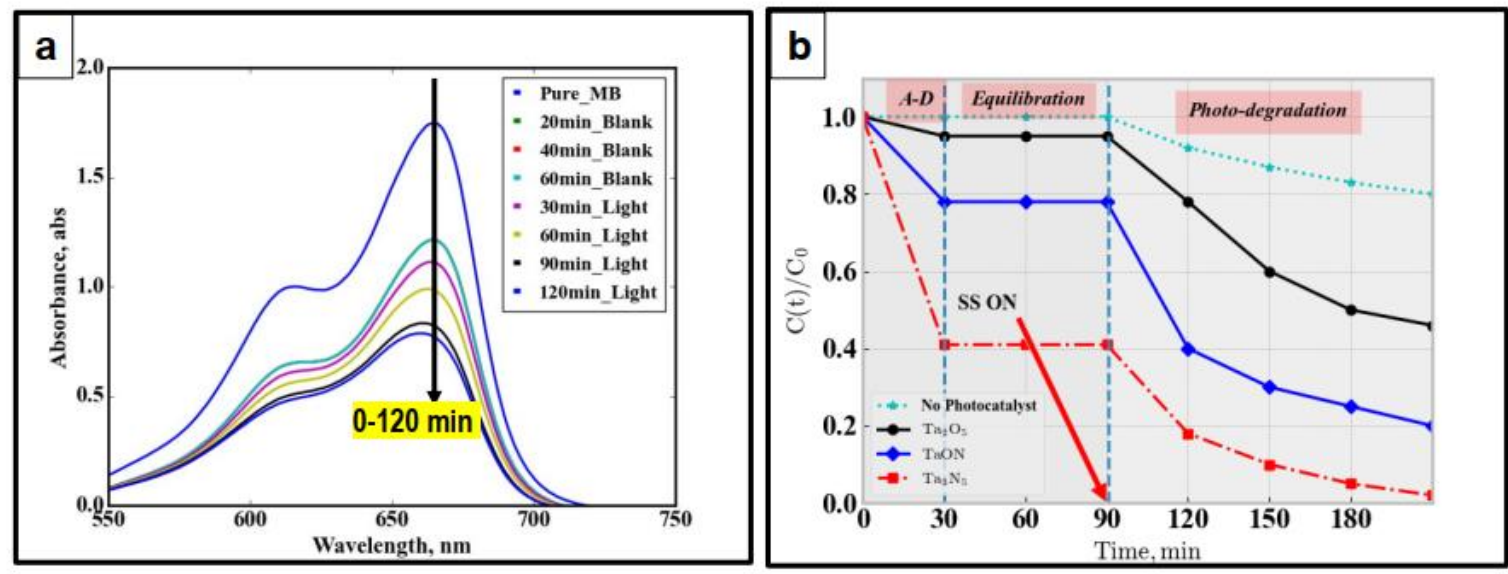

Figure 5. (a) A set of representative absorbance spectra of the dye, methylene blue, $28.6 \mathrm{mM} \mathrm{MB}$, in the presence of $0.1 \mathrm{~g}$ in-house synthesized $\mathrm{Ta}_{2} \mathrm{O}_{5}$ photocatalyst indicating a gradual decrease under Xe lamp solar simulator (SS). (b) A comparison of the adsorption, equilibration, and photocatalytic conversion of $\mathrm{MB}$ in the presence of $0.1 \mathrm{~g} \mathrm{Ta}_{2} \mathrm{O}_{5}, \mathrm{TaON}$, and $\mathrm{Ta}_{3} \mathrm{~N}_{5}$ each is presented.

\subsubsection{Comparing Photoactivity of In-House $\mathrm{Ta}_{2} \mathrm{O}_{5}, \mathrm{TaON}$, and $\mathrm{Ta}_{3} \mathrm{~N}_{5}$}

The activity of in-house $\mathrm{Ta}_{2} \mathrm{O}_{5}$ was compared with TaON (synthesized by using our aforementioned novel approach) and $\mathrm{Ta}_{3} \mathrm{~N}_{5}$ (produced by conventional thermally reduced processes) for $\mathrm{MB}$ degradation. As can be seen, the dark absorbance phase during equilibration is remarkably different for the two photocatalysts. Interestingly, a significant drop in absorbance of the dye is noted during dark equilibration with $\mathrm{TaON}$ and $\mathrm{Ta}_{3} \mathrm{~N}_{5}$. It is also to be noted that the adsorption of $\mathrm{MB}$ increases significantly as the nitrogen content in the nitrogen-derivatives of $\mathrm{Ta}_{2} \mathrm{O}_{5}$ is increased. The results in Figure $5 \mathrm{~b}$ highlight the observation that $\mathrm{TaON}$ and $\mathrm{Ta}_{3} \mathrm{~N}_{5}$ contribute significantly more towards $\mathrm{MB}$ conversion. A conversion of $64 \%, 80 \%$, and $98 \%$ are noted for the $\mathrm{Ta}_{2} \mathrm{O}_{5}, \mathrm{TaON}$, and $\mathrm{Ta}_{3} \mathrm{~N}_{5}$ respectively using Xe lamp illumination. The higher conversion with $\mathrm{Ta}_{3} \mathrm{~N}_{5}$ compared to TaON is attributed to the greater absorbance of the MB on the former.

\section{Discussion}

The physical/surface, optical, and photocatalytic studies discussed thus far point to the viability of the (i) use of the surfactant-based method to produce well controlled tantalum-based oxide photocatalysts, (ii) their conversion by nitridation to $\mathrm{TaON} / \mathrm{Ta}_{3} \mathrm{~N}_{5}$, and (iii) their application towards pollutant remediation. Some of the immediate and obvious questions that arise from the preceding analyses are: What is the reason for improved photocatalysis? How stable is the photocatalyst upon repeated use? How does nitridation lead to enhancement in the photocatalytic activity beyond the parent $\mathrm{Ta}_{2} \mathrm{O}_{5}$ performance? This discussion addresses each of these questions and also highlights some of the limits of the nitridation process. 


\subsection{Chronoamperometry (j/t) and Linear Sweep Voltammetry (j/V) Measurements}

The analysis of photoelectrochemical (PEC) data offer valuable information into the separation and transport mechanisms of charges photogenerated in the catalysts upon illumination. This approach allows for tracking both hole and electrons generated in the catalysts and can be correlated with the photocatalytic activity $[47,48]$. The chronoamperometry or $\mathrm{j} / \mathrm{t}$ responses of the commercial and in-house synthesized $\mathrm{Ta}_{2} \mathrm{O}_{5}$ obtained with a $\mathrm{Pt}$ wire as the counter electrode in a 3-electrode PEC cell are shown in the Figure S3A. The multiple on-off chop light cycles show that the response in both films are light triggered and the reproducible nature of these responses indicate that the films formed on the conducting glass slides are reproducible (Figure 6A). Further, the photocurrent after complete nitration to $\mathrm{Ta}_{3} \mathrm{~N}_{5}$ is significantly higher. The bar graph in Figure $6 \mathrm{~B}$ provides a summary of the average photocurrent from $\mathrm{Ta}_{2} \mathrm{O}_{5}, \mathrm{TaON}$, and $\mathrm{Ta}_{3} \mathrm{~N}_{5}$. The inserts of Figure $6 \mathrm{~B}$ shows the photographs of the films after the PEC measurements, indicating they are stable (do not delaminate). The in-house $\mathrm{Ta}_{2} \mathrm{O}_{5}$ shows a photocurrent of $0.42 \mu \mathrm{A} / \mathrm{cm}^{2}$ while the commercial $\mathrm{Ta}_{2} \mathrm{O}_{5}$ response is approximately $0.41 \mu \mathrm{A} / \mathrm{cm}^{2}$. The slightly higher photocurrent with the in-house $\mathrm{Ta}_{2} \mathrm{O}_{5}$ could be attributed to the difference in the physical dimensions of the nanoparticles and/or the improved photoactivity of this film but has to be verified using alternative approaches (discussed below). At the same time, the corresponding photocurrent using TaON and $\mathrm{Ta}_{3} \mathrm{~N}_{5}$ are observed to be $\sim 2 \pm 0.5 \mu \mathrm{A} / \mathrm{cm}^{2}$ and $2.2 \pm 0.2 \mu \mathrm{A} / \mathrm{cm}^{2}$ respectively-an almost 9-10-fold increase in the photoresponse. This shows that the photoelectrons generated in the nitrided samples are significantly higher compared to the oxide and can be attributed to the effective visible light utilization resulting from the lowered bandgap.

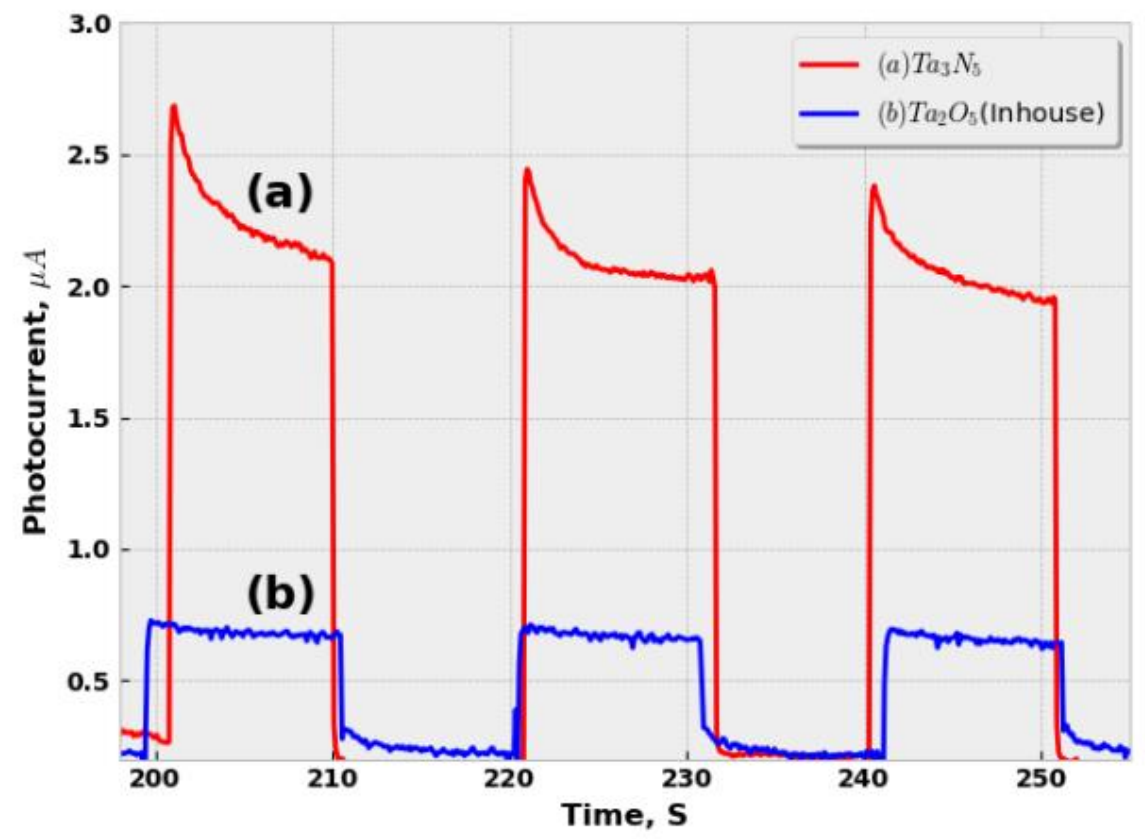

(A)

Figure 6. Cont. 


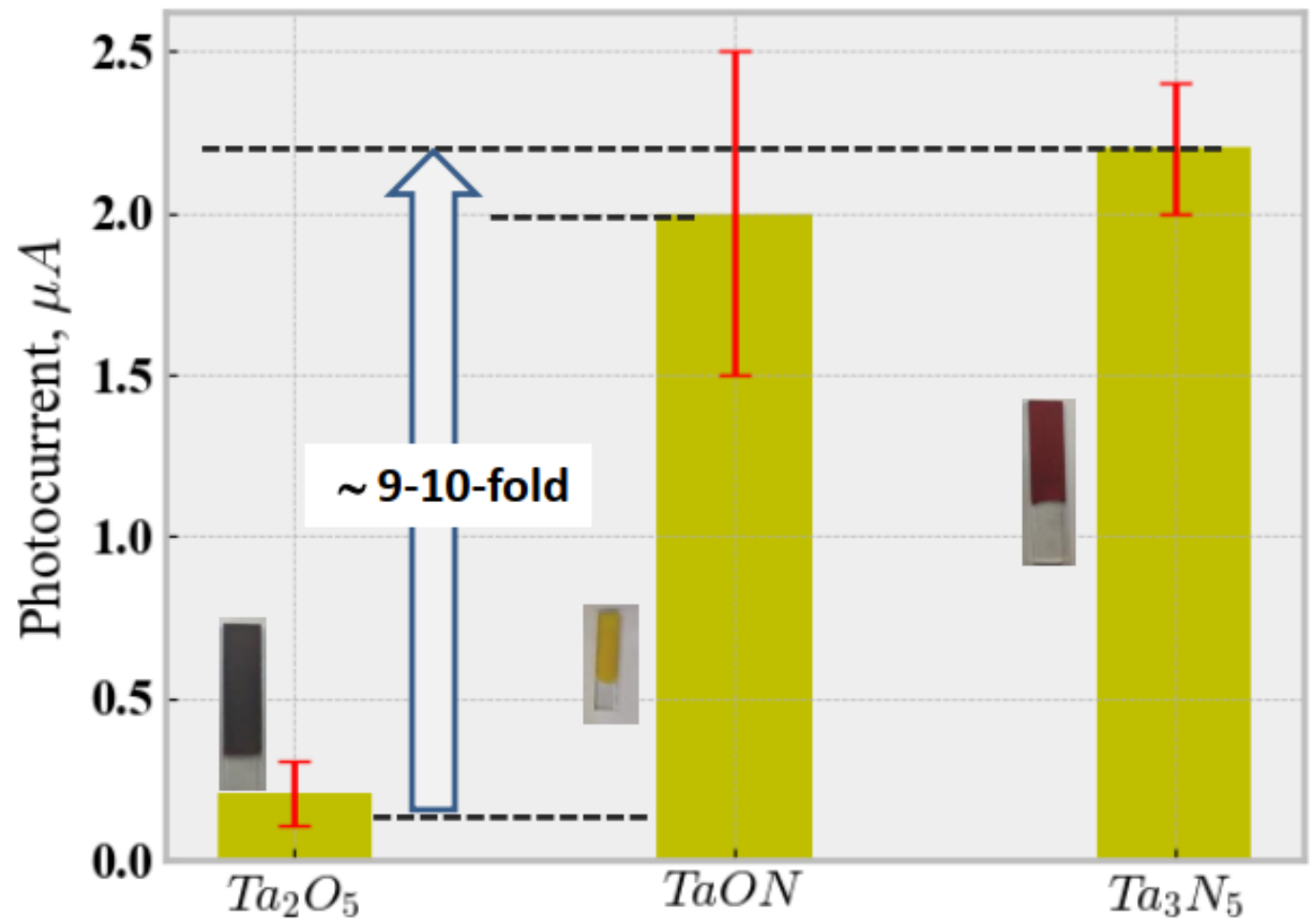

(B)

Figure 6. (A) The chronoamperometry (i/t) responses for the as-synthesized $\mathrm{Ta}_{2} \mathrm{O}_{5}$ and $\mathrm{Ta}_{3} \mathrm{~N}_{5}$ samples. (Operating conditions: Pt counter electrode, leak-free $\mathrm{Ag} / \mathrm{AgCl}$ (in $0.2 \mathrm{M} \mathrm{NaOH}$ ) as the reference electrode and sample coated ITO slide as a working electrode. Light intensity: $80 \mathrm{~mW} / \mathrm{cm}^{2}$, applied potential $\mu \mathrm{M}$ ). (B) Photocurrent responses from $\mathrm{Ta}_{2} \mathrm{O}_{5}$ and its subsequent nitrogen derivatives. The error bars represent the range obtained with different films. (Operating conditions: Pt counter electrode, leak-free $\mathrm{Ag} / \mathrm{AgCl}$ (in $0.2 \mathrm{M} \mathrm{NaOH}$ ) as the reference electrode and sample coated ITO slide as a working electrode. Light intensity: $80 \mathrm{~mW} / \mathrm{cm}^{2}$, no external bias applied).

\subsection{Electrochemical Impedance Spectroscopy (EIS)}

The basis for performing the EIS analysis on the tantalum-based photocatalysts is to gain insights into film properties such as the $\mathrm{n}-/ \mathrm{p}$-characteristics and a qualitative estimate of the extent of charge separation $[49,50]$. The plot of the impedance response for the $\mathrm{Ta}_{2} \mathrm{O}_{5}$ and $\mathrm{Ta}_{3} \mathrm{~N}_{5}$ photocatalyst films is shown in Figure S4. Firstly, the positive slope evident from all of the samples indicates that the $\mathrm{Ta}_{2} \mathrm{O}_{5}$, $\mathrm{TaON}$, and $\mathrm{Ta}_{3} \mathrm{~N}_{5}$ demonstrate n-type characteristics. Secondly, the $\mathrm{Ta}_{2} \mathrm{O}_{5}$ in-house sample shows a low radius of curvature compared to the commercial sample indicating that charge separation is better with the in-house samples. Finally, the application of the nitridation process to $\mathrm{Ta}_{2} \mathrm{O}_{5}$ to form $\mathrm{TaON}$ and $\mathrm{Ta}_{3} \mathrm{~N}_{5}$ is beneficial as it shows the lowest radius of curvature indicating the most effective transport among the three photoactive films. Thus, the series of PEC measurements indicate that (i) the in-house $\mathrm{Ta}_{2} \mathrm{O}_{5}$ and $\mathrm{Ta}_{3} \mathrm{~N}_{5}$ demonstrate photocurrent generation, (ii) reproducible and stable response, and (iii) the $\mathrm{Ta}_{3} \mathrm{~N}_{5}$ demonstrates a distinguishable enhancement in the photocurrent response compared to the $\mathrm{Ta}_{2} \mathrm{O}_{5}$ films which can be attributed to the better charge separation, transport across the film thickness, and collection at the underlying ITO plate.

\subsection{Evaluation of the Reusability of the Photocatalysts}

$\mathrm{MB}$ is a complex molecule with multiple benzene rings and functional groups that results in its photodegradation through several intermediates [44]. Therefore, it is reasonable to evaluate the re-use 
of the photocatalysts since the parent dye or intermediate could be adsorbed on the photocatalyst sites effectively preventing the site from further participating in degradation. Therefore, after the first use, the $\mathrm{Ta}_{2} \mathrm{O}_{5}$ photocatalyst was removed, washed, centrifuged, and dried in the presence of a positive draft of enriched oxygen at a temperature of $400{ }^{\circ} \mathrm{C}$. This oxidative approach has been shown earlier to aid in recovering most of the photoactivity of oxide catalysts [51]. The results of such a treatment followed by a second and a third use are shown in Figure 7 along with the performance of the pristine catalyst as a comparison. It may be noted that the re-used catalyst shows the same activity as the pristine indicating that the photoactive surfaces are available intact after the oxidative treatment. This analysis indicates that it is possible to reuse the photocatalyst making it an effective and viable option for photo-assisted environmental remediation.

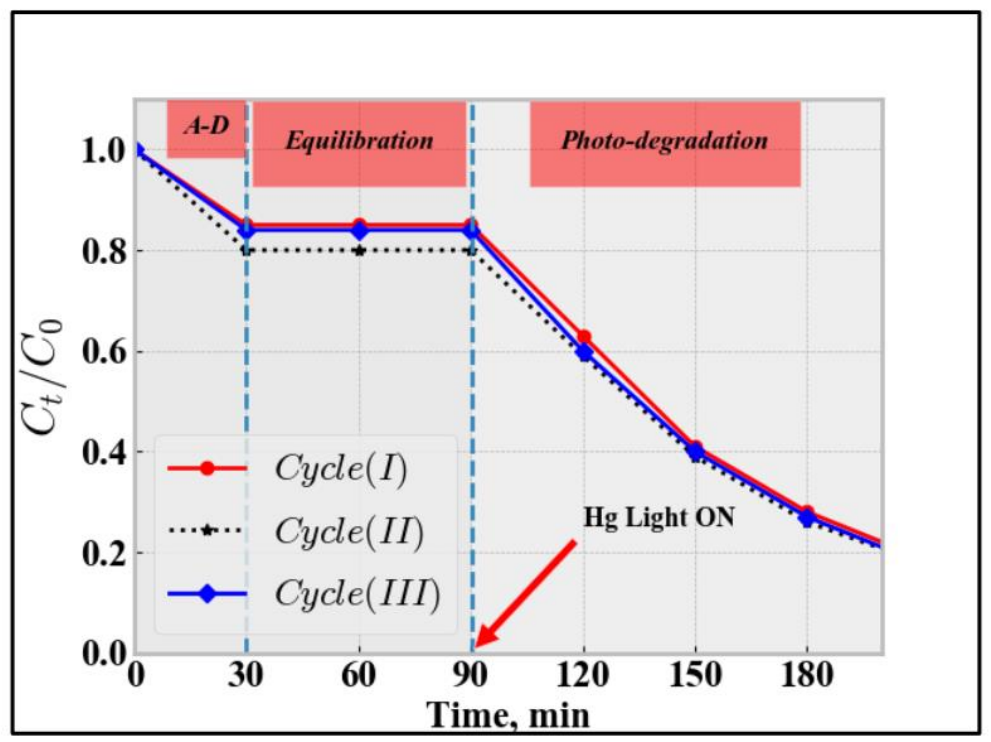

Figure 7. A comparison of the activity of the photocatalyst TaON toward the degradation of MB after multiple reuse cycles. Following the first time use the catalyst was recovered by oxidative treatment and repeated. as shown. (28.6 $\mu \mathrm{M} \mathrm{MB}$, air equilibrated UV-vis illumination).

\subsection{Methylene Blue Oxidation Routes}

Although it has been reported that tantalum based photocatalysts $\left(\mathrm{Ta}_{2} \mathrm{O}_{5},[52,53]\right.$ and its nitrogen substituted compounds $[54,55]$ ) can degrade $\mathrm{MB}$, the mechanism of the photocatalytic activity on $\mathrm{Ta}_{3} \mathrm{~N}_{5}$ or comparing it with $\mathrm{Ta}_{2} \mathrm{O}_{5}$ is not yet reported. A preliminary analysis of the possible mechanism of photodegradation based on reports using these and other photocatalysts used in MB photodegradation is therefore presented here first. The direct photolytic degradation of methylene blue is possible using UV-vis light because of its ionic characteristics [56] but negligible photoactivity towards MB conversion is noted under visible light, specifically in the range between 400 and $500 \mathrm{~nm}$ where MB does not absorb as much as it does further into the red [57,58]. Elsewhere, it is also reported that both single metal large bandgap oxide such as $\mathrm{Ta}_{2} \mathrm{O}_{5}$ [52] or a composite photocatalysts such as $\mathrm{InVO}_{4}-\mathrm{BiVO}_{4}$ [59], produce $\mathrm{e} / \mathrm{h}$ pairs simultaneously that individually lead to hydroxyl radical formation which cause MB degradation. Even in a non-oxide based material, such as a sulfide-based visible light driven photocatalyst, a mechanism involving both e/h driven hydroxyl radical formation (e.g., CdS) for MB degradation and $\mathrm{CB}$ electrons-driven formation of superoxide which in turn can produce hydroxyl radicals for MB degradation is reported [60].

The observed enhancement in overall MB conversion by as-synthesized $\mathrm{Ta}_{2} \mathrm{O}_{5}, \mathrm{TaON}$ and $\mathrm{Ta}_{3} \mathrm{~N}_{5}\left(\zeta_{\mathrm{Ta}_{2} \mathrm{O}_{5}}: 64 \%<\zeta_{\mathrm{TaON}}: 80 \%<\zeta_{\mathrm{Ta}_{3 N_{5}}}: 98 \%\right.$; Figure $\left.5 \mathrm{~b}\right)$ can be attributed to two clearly elucidated processes: 
(i) Adsorption of MB molecules on catalyst surface: The intrinsic atomic defects introduced on the surface of the crystal lattices during their synthesis as inferred from SEM analysis in this study are proposed to provide better anchorage to the MB molecules. Electrostatic interaction between $\mathrm{MB}$ and defect-generated charge centers in the catalyst surface is a possibility behind improved adsorption.

Therefore, we hypothesize that any additional synthesis step carried out in obtaining the nitrogen derivatives of $\mathrm{Ta}_{2} \mathrm{O}_{5}: \mathrm{TaON}$ and $\mathrm{Ta}_{3} \mathrm{~N}_{5}$ introduces additional crystal defects on the catalyst surface, thereby introducing a larger number of intrinsic charge centers that act as effective anchors to the cationic MB molecules. Accordingly, the significant improvement in the adsorption of MB molecules on $\mathrm{Ta}_{3} \mathrm{~N}_{5}$ catalyst surface as inferred from Figure $5 \mathrm{~b}$ and Table 1 can be attributed to the highest number of surface defects introduced during longer nitridation period ( $15 \mathrm{~h})$ as compared to that for $\mathrm{TaON}(1.5 \mathrm{~h})$.

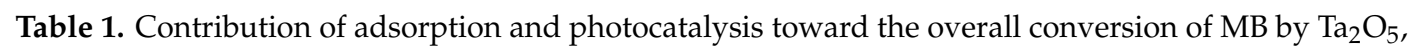
$\mathrm{TaON}$, and $\mathrm{Ta}_{3} \mathrm{~N}_{5}$. Significant improvement in adsorption-contribution toward MB removal can be attributed to the better anchorage provided to MB molecules by nitrided catalysts due to the increased atomic defects.

\begin{tabular}{ccc}
\hline Catalyst & Adsorption Contribution (\%) & Photocatalysis Contribution (\%) \\
\hline $\mathrm{Ta}_{2} \mathrm{O}_{5}$ & $\sim 5$ & $\sim 60$ \\
$\mathrm{TaON}_{\mathrm{O} N}$ & 20 & 60 \\
$\mathrm{Ta}_{3} \mathrm{~N}_{5}$ & 40 & 58 \\
\hline
\end{tabular}

Electron paramagnetic resonance (EPR) analysis of each of the catalysts is undergoing for a thorough understanding of the physico-chemical nature of the defects.

(ii) Valence band edge position and reduced bandgap: The contribution from adsorption-desorption (A-D) equilibration toward overall $\mathrm{MB}$ conversion under dark conditions significantly differs in cases of $\mathrm{Ta}_{2} \mathrm{O}_{5}, \mathrm{TaON}$ and $\mathrm{Ta}_{3} \mathrm{~N}_{5}$ while the contribution from photocatalytic removal (after the SS is turned on) does not significantly differ (Figure $5 b$ ). This can be explained by the lowered optical bandgap complimenting with the shallower valence band edge of $\mathrm{TaON}$ and $\mathrm{Ta}_{3} \mathrm{~N}_{5}$. It is well known from experimental as well as first principle calculations that the conduction band edge positions of $\mathrm{Ta}_{2} \mathrm{O}_{5}, \mathrm{TaON}$, and $\mathrm{Ta}_{3} \mathrm{~N}_{5}$ are largely similar while the valence band edges get shallower as the nitrogen content increases in the catalysts $[15,61,62]$. As-synthesized $\mathrm{Ta}_{2} \mathrm{O}_{5}, \mathrm{TaON}$ and $\mathrm{Ta}_{3} \mathrm{~N}_{5}$ photocatalysts in this work clearly demonstrate similar responses such as the shift of apparent flatband potential $\left(\mathrm{E}_{\mathrm{fb}}\right)$ toward negative potential (Table 2, Figure S3B) and the reduction in bandgap (Figure 4).

Table 2. Apparent flat-band potential $\left(\mathrm{E}_{\mathrm{fb}}\right)$ for $\mathrm{Ta}_{2} \mathrm{O}_{5}$ and its subsequent nitrogen derivatives. (Refer to Figure $\mathrm{S} 4$ for the J/V response).

\begin{tabular}{|c|c|}
\hline Sample & $E_{f b}, V$ \\
\hline $\mathrm{Ta}_{2} \mathrm{O}_{5}$ (As-synthesized) & $-0.63 \pm 0.3$ \\
\hline $\mathrm{TaON}$ & $-0.95 \pm 0.3$ \\
\hline $\mathrm{Ta}_{3} \mathrm{~N}_{5}$ & $-0.96 \pm 0.3$ \\
\hline
\end{tabular}

Consequently, $\mathrm{Ta}_{2} \mathrm{O}_{5}\left(\mathrm{E}_{\mathrm{g}}=3.66 \mathrm{eV}\right)$ offers the highest capability toward $\mathrm{MB}$ oxidation owing to its deepest valence band edge. $\mathrm{TaON}\left(\mathrm{E}_{\mathrm{g}}=2.21 \mathrm{eV}\right)$ and $\mathrm{Ta}_{3} \mathrm{~N}_{5}\left(\mathrm{E}_{\mathrm{g}}=1.71 \mathrm{eV}\right)$ have shallower band edges that offer lesser oxidation capability of $\mathrm{MB}$ molecules as compared to $\mathrm{Ta}_{2} \mathrm{O}_{5}$. On the other hand, $\mathrm{TaON}$ and $\mathrm{Ta}_{3} \mathrm{~N}_{5}$ absorb a larger fraction of the solar spectrum (light source is Xe light solar simulator, $\mathrm{AM}=1.5$ ) owing to their reduced bandgaps. This fact is verified by the 9-10-fold larger improvement in $\mathrm{J} / \mathrm{t}$ response by $\mathrm{TaON}$ and $\mathrm{Ta}_{3} \mathrm{~N}_{5}$ as compared to $\mathrm{Ta}_{2} \mathrm{O}_{5}$ (Figure $6 \mathrm{~B}$ ). Consequently, the availability of e/h pairs under solar simulator illumination follows the order $\mathrm{Ta}_{2} \mathrm{O}_{5}<\mathrm{TaON}<\mathrm{Ta}_{3} \mathrm{~N}_{5}$, and the depth of the valence band edge follows the order $\mathrm{Ta}_{2} \mathrm{O}_{5}>\mathrm{TaON}>\mathrm{Ta}_{3} \mathrm{~N}_{5}$ under simulated solar irradiation. Thus, the abundance of $\mathrm{e} / \mathrm{h}$ pairs and depth of valence band edge position in the catalysts produce a complimenting redox process that results in the observed constancy of photocatalytic MB removal. 
Therefore, a hole driven oxidation of hydroxyl ions to form hydroxyl radicals and electron driven formation of superoxide ion, which eventually leads to the formation of hydroxyl radicals, is suggested.

\section{Experimental}

Methylene Blue (M9140-25G, Sigma Aldrich, St. Louis, MO, USA), Ammonia (Anhydrous UN1005, Air gas, Reno, NV, USA), Ammonium Hydroxide (Fisher Chemical, Lot\# 174361, Hampton, NH, USA) were purchased from commercial vendors as indicated in the brackets. Ultra-high purity water for making the solution was obtained using the Millipore water purification system (resistivity $=18.2 \mathrm{M} \Omega \cdot \mathrm{cm}$ ). The chemicals were used "as is" without any alteration or purification for synthesis, as described in the protocol detailed in Figure 8a,b. A suspension of the synthesized material is prepared with the dye in water. A steadily increasing loading of $0.05 \mathrm{~g}, 0.075 \mathrm{~g}, 0.1 \mathrm{~g}$, and $0.15 \mathrm{~g}$ of the photocatalyst $\mathrm{Ta}_{2} \mathrm{O}_{5}, \mathrm{TaON}$, or $\mathrm{Ta}_{3} \mathrm{~N}_{5}$ and $200 \mathrm{~mL}$ volume of $28.6 \mu \mathrm{M}$ Methylene Blue solution was ultrasonicated for three minutes and then stirred magnetically. It was later transferred to a borosilicate photocatalytic reactor for experimental analysis.

(a)

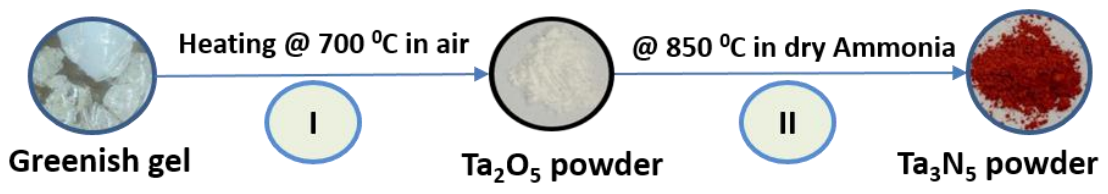

(b)

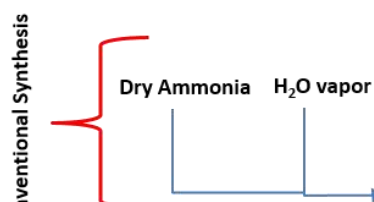

(b)
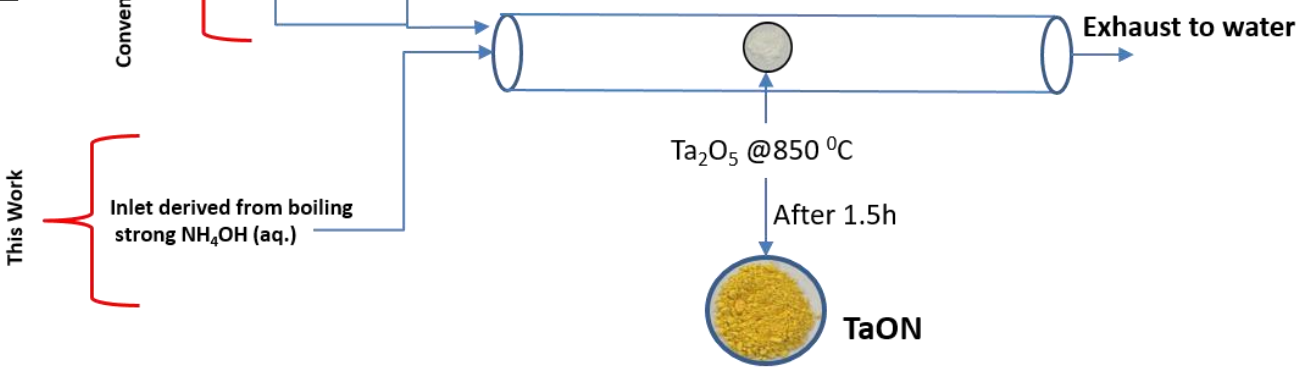

Figure 8. (a) The step-by-step process to synthesize (I) the oxide phase $\left(\mathrm{Ta}_{2} \mathrm{O}_{5}\right)$ from Ta-Precursor, and (II) the subsequent thermal treatment step for its complete nitridation $\left(\mathrm{Ta}_{3} \mathrm{~N}_{5}\right)$ [63]. (b) The simplified method of nitridation for synthesizing TaON using $\mathrm{NH}_{4} \mathrm{OH}$ solution $\left(\mathrm{NH}_{4} \mathrm{OH}: \mathrm{H}_{2} \mathrm{O}(v / v)=150: 100\right.$, temperature of the heating bath (ethylene glycol): $300^{\circ} \mathrm{C}$ ).

\subsection{Synthesis Approach}

The popular method used in the synthesis of $\mathrm{Ta}_{2} \mathrm{O}_{5}$ involves tantalum chloride as a precursor [52]. Further, from our previous studies, the use of glacial acetic acid has indicated the formation of oxides with a high surface area that maintain stability [64]. Besides, ethoxide precursors have reportedly been known for interactions resulting in stable complexes with metal cations in acidic media $[63,65]$. Based on these references, in our previous work, we investigated the use of an ethoxide precursor with glacial acetic acid implementing the sol-gel process [63]. We studied the complete nitridation of as-synthesized $\mathrm{Ta}_{2} \mathrm{O}_{5}$ crystals in the same work to achieve single phase $\mathrm{Ta}_{3} \mathrm{~N}_{5}$, and herein we present a novel partial nitridation technique to achieve single phase $\mathrm{TaON}$. Partial nitridation can lead to $\mathrm{TaO}_{X} \mathrm{~N}_{Y}$, where $x \neq y$. In particular, the strict requirement of finding an optimal ratio of oxygen to nitrogen as demanded by the most stable phase of TaON imposes challenges during its synthesis [15]. Traditionally, the common route of synthesizing $\mathrm{TaON}$ has been the gas phase nitridation of corresponding oxides 
at high temperature. Ammonia, the most common nitrogen source used in such synthesis routes, is shown to produce the fully reduced form of $\mathrm{Ta}_{2} \mathrm{O}_{5}$ (i.e., $\mathrm{Ta}_{3} \mathrm{~N}_{5}$ ) $[63,66-68]$ while moist ammonia is reported to thermodynamically support the yield of TaON [69-71]. Challenge of controlling the precise flowrate of multiple fluids in such approaches often leads to the formation of various mixed (oxy)nitrides. On the other hand, the use of gaseous ammonia is not always a first choice-neither in research facilities nor in commercial plants due to the associated hazards [72]. Additional challenges are encountered due to the requirement of a precise flow of water vapor (together with the flow of dry ammonia) to produce single phase TaON [73]. Therefore, the traditionally popular methods of synthesizing TaON are prone to restrict absolute reproducibility of TaON $[71,73,74]$.

A detailed experimental setup for the simplified method for synthesizing single phase TaON reported in this discussion is presented in Figure 8b, Figure S1. The primary idea presented here is to replace the complex inlet of multiple phases in traditional synthesis protocols. Inspired from the fact that the gaseous phase of ammonia $\left(\mathrm{NH}_{3}\right)$ reacts reproducibly with water $\left(\mathrm{H}_{2} \mathrm{O}\right)$ to give liquid phase ammonium hydroxide $\left(\mathrm{NH}_{4} \mathrm{OH}\right)$, we hypothesized and successfully verified that a simpler-to-handle liquid phase of $\mathrm{NH}_{4} \mathrm{OH}$ can replace the complex nitrogen source used in traditional methods (dry ammonia together with water vapor). In such an approach, the nitridation rate can be controlled as a function of two easily controllable parameters: $\mathrm{pH}$ of $\mathrm{NH}_{4} \mathrm{OH}$ solution and the heating bath temperature. Tuning of these parameters offers an easier option for selective nitridation of $\mathrm{Ta}_{2} \mathrm{O}_{5}$ nanocrystals and hence single phase TaON. As the reaction between $\mathrm{NH}_{3}$ and $\mathrm{H}_{2} \mathrm{O}$ is reversible, the liquid phase $\mathrm{NH}_{4} \mathrm{OH}$ gives off a mixture of ammonia gas and water vapor when heated, and it serves as the reliable source of humidified nitrogen as required in the conventional synthesis of $\mathrm{TaON}$.

\subsection{Material Characterization}

The characterization of the photocatalysts was performed using several complementary tools. A Hitachi ${ }^{\circledR}$ S-4700 scanning electron microscope (SEM) (Hitachi, Tokyo, Japan) was used to examine the physical features of the powder. An attached electron dispersive spectrometer (EDS) (Hitachi, Tokyo, Japan) was used to determine the photocatalyst composition. Crystalline features of the photocatalysts were examined using an XRD $(\mathrm{Cu}-\mathrm{K} \alpha, \lambda=1.5418 \AA)$ instrument from Bruker (D2 Phaser) (Bruker, Madison, WI, USA) and the Scherer equation was performed in order to determine the crystalline size of nanoparticles. High resolution transmission electron microscopy ((HR)TEM) (Hitachi, Tokyo, Japan) analysis was performed using a JEOL 2100F instrument equipped with a selected area electron diffraction (SAED) analyzer (Hitachi, Tokyo, Japan). The optical properties of the powder were examined using a UV-vis diffuse absorbance measurement with a Shimadzu UV 2501PC spectrophotometer (Shimadzu, Columbia, MD, USA). The BET surface area of the synthesized materials were determined using a micromeritics system (model flow sorb II-2300) (Micromeritics, Hannover, Germany).

\subsection{Determination of Photocatalytic Properties}

The photocatalytic reactions were performed using two light sources (details in Table S1). First, a slurry reactor comprising a tubular borosilicate vessel of $500 \mathrm{~mL}$ volume with a lamp (450 W Hg vapor source) introduced in the annulus of the vessel was used along with jacketed temperature control achieved using a stream of cooling water. The details of the reactor assembly are presented elsewhere. The photocatalysts in quantities of $0.05 \mathrm{~g}, 0.75 \mathrm{~g}, 0.1 \mathrm{~g}$, and $0.15 \mathrm{~g}$ were used in subsequent experiments by making as suspensions in $200 \mathrm{~mL}$ of an aqueous methylene blue $(28.6 \mu \mathrm{M})$. Second, an open configuration comprising of a batch type reactor with top down illumination using a $580 \mathrm{~W}$ Xenon lamp as the light source was used. The latter reactor allowed for facilitating visible light illumination experiments. Since $\mathrm{Hg}$ lamp is not a good source to compare the performance of photocatalysts with varying bandgaps, Xe lamp with lower UV content than Hg lamp was used as a solar simulator $(\mathrm{AM}=1.5)$ in the photocatalytic degradation studies. In both cases, the photocatalyst was kept 
suspended by continuous stirring to ensure homogeneous distribution in the MB solution. The lamp was turned on only after the dye equilibrated on the catalysts surface, i.e., a saturation plateau for the dye concentration was achieved $(\sim 1.5 \mathrm{~h})$. The $5 \mathrm{~mL}$ slurry aliquots were sampled every $30 \mathrm{~min}$ in a plastic vial and centrifuged $(\sim 20 \mathrm{~min})$ to remove the suspended particles. Several successive samples were probed at regular intervals using a Shimadzu UV-vis-2501PC spectrophotometer (Shimadzu, Columbia, MD, USA). For reusability tests, part of the sample $(0.1 \mathrm{~g})$ was recovered after centrifuging the $0.3 \mathrm{~g}$ sample-slurry, extracting the maximum possible precipitate. The adsorbed residue was burned off from the dried sample under oxidative conditions at $400{ }^{\circ} \mathrm{C}$ over a gradual stream of air.

\subsection{Determination of Photoelectrochemical Properties}

The photoelectrochemical measurements were performed using a potentiostat/galvanostat (Autolab PGStat series, Metrohm, Riverview, FL, USA). The measurements were recorded for films of the photocatalyst prepared by depositing an aqueous suspension of the photocatalyst slurry on conducting (FTO) glass slide followed by $\mathrm{N}_{2}$ annealing at $350^{\circ} \mathrm{C}$. Chronoamperometry, Linear sweep voltammetry, and measurements for bandgap estimation (Tauc plots) were obtained using $0.2 \mathrm{M}$ aqueous $\mathrm{NaOH}$. A Xe lamp was used as a light source with a $\mathrm{CuSO}_{4}$ filter for high $\mathrm{UV}$ cut off. A Pt mesh was used as the counter electrode and $\mathrm{Ag} / \mathrm{AgCl}$ was used as a reference.

\section{Conclusions}

A simplified and extremely reproducible approach to partial nitridation of $\mathrm{Ta}_{2} \mathrm{O}_{5}$ resulting in single phase $\mathrm{TaON}$ is successfully demonstrated. The physical features, phase evolution, and optical properties are systematically analyzed. Particles ranging from $\phi=30-40 \mathrm{~nm}, 40-50 \mathrm{~nm}$, and 30-40 nm for $\mathrm{Ta}_{2} \mathrm{O}_{5}$, $\mathrm{TaON}$, and $\mathrm{Ta}_{3} \mathrm{~N}_{5}$ respectively is reported. The photodegradation of a representative cationic dye, methylene blue, was effectively carried out with $\sim 95 \%$ conversion of the dye at various loading amounts under solar simulator. The photoactivity of the novel catalyst was further examined after subjecting to mild oxidative thermal treatment. The catalyst activity matches that of non-used catalyst, post thermal treatment. The main features of the photocatalysts identified include: (i) synthesis of well-faceted oxides, oxynitrides and nitrides, (ii) increased adsorption of dye and visible light activity noted with the increase of nitrogen content in the nitrogen derivatives of the oxide catalyst, and (iii) enhanced separation of photogenerated charges contributes to better photoactivity as evidenced from a series of complementary photoelectrochemical measurements (primarily a 9-10 fold increase in photocurrent as a function of increased nitridation). Salient features of the novel $\mathrm{TaON}$ synthesis approach include (i) a robustly reproducible single phase $\mathrm{TaON}$ synthesis method that is least associated with gaseous hazards, (ii) a simplified protocol suitable for laboratory as well as largely scalable synthesis of single phase $\mathrm{TaON}$, and (iii) a cost-effective miniaturized method that replaces flowmeters with a constant temperature bath, and costly anhydrous ammonia gas with cost-friendly ammonium hydroxide.

Supplementary Materials: The following are available online at http://www.mdpi.com/2073-4344/10/10/1128/s1, Figure S1: The schematic of the simplified TaON synthesis protocol, Table S1: Optical bands emitted from the Mercury $(\mathrm{Hg})$ lamp, Figure S2: Scanning electron microscope image of commercial $\mathrm{Ta}_{2} \mathrm{O}_{5}$ sample, Figure S3: (A) Chrono-amperometry (i/t) responses and (B) Linear sweep voltametry of Commercial and in-house $\mathrm{Ta}_{2} \mathrm{O}_{5}$. Figure S4: Electrochemical impedance analysis (EIS, Nyquist Plots) of (a) as-synthesized $\mathrm{Ta}_{2} \mathrm{O}_{5}$, (b) $\mathrm{TaON}$, and (c) $\mathrm{Ta}_{3} \mathrm{~N}_{5}$.

Author Contributions: V.K. and V.S. designed this work, and V.K. prepared the manuscript. The experiments and data analysis were carried out by V.K., N.O.B. and E.S.-H. V.K., V.S., E.S.-H., D.C., N.O.B., D.W.B. discussed the results and implications and commented on the manuscript at all stages. All authors have read and agreed to the published version of the manuscript.

Funding: This research received no external funding.

Acknowledgments: The support from the Alexander von Humboldt foundation to R.S.V. is acknowledged. Notable contribution from Cara DuMonte as an undergraduate intern is also acknowledged. The assistance provided by Mojtaba Ahmedian with obtaining SEM and HRTEM images is gratefully acknowledged. The support 
of the National Science Foundation (CHE-1429768) for the purchase of the powder X-ray diffractometer is gratefully acknowledged.

Conflicts of Interest: The authors declare no conflict of interest.

\section{References}

1. Zhang, H.; Chen, G.; Bahnemann, D.W. Photoelectrocatalytic materials for environmental applications. J. Mater. Chem. 2009, 19, 5089-5121. [CrossRef]

2. Rajeshwar, K.; Osugi, M.E.; Chanmanee, W.; Chenthamarakshan, C.R.; Zanoni, M.V.; Kajitvichyanukul, P.; Krishnan-Ayer, R. Heterogeneous photocatalytic treatment of organic dyes in air and aqueous media. J. Photochem. Photobiol. C Photochem. Rev. 2008, 9, 171-192. [CrossRef]

3. Dolat, D.; Mozia, S.; Ohtani, B.; Morawski, A.W. Nitrogen, iron-single modified $\left(\mathrm{N}-\mathrm{TiO}_{2}, \mathrm{Fe}_{-} \mathrm{TiO}_{2}\right)$ and co-modified $\left(\mathrm{Fe}, \mathrm{N}-\mathrm{TiO}_{2}\right)$ rutile titanium dioxide as visible-light active photocatalysts. Chem. Eng. J. 2013, 225, 358-364. [CrossRef]

4. Tang, Z.-R.; Li, F.; Zhang, Y.; Fu, X.; Xu, Y.-J. Composites of Titanate Nanotube and Carbon Nanotube as Photocatalyst with High Mineralization Ratio for Gas-Phase Degradation of Volatile Aromatic Pollutant. J. Phys. Chem. C 2011, 115, 7880-7886. [CrossRef]

5. Khanal, V.; Ragsdale, W.; Gupta, S.; Subramanian, V.R. Insights into the photoactivity of iron modified bismuth titanate (Fe_BTO) nanoparticles. Catal. Today 2018, 300, 81-88. [CrossRef]

6. Kochuveedu, S.T.; Jang, Y.H.; Kim, D.H. A study on the mechanism for the interaction of light with noble metal-metal oxide semiconductor nanostructures for various photophysical applications. Chem. Soc. Rev. 2013, 42, 8467. [CrossRef]

7. Hernández, S.; Cauda, V.; Chiodoni, A.; Dallorto, S.; Sacco, A.; Hidalgo, D.; Celasco, E.; Pirri, C.F. Optimization of 1D ZnO@TiO 2 Core-Shell Nanostructures for Enhanced Photoelectrochemical Water Splitting under Solar Light Illumination. ACS Appl. Mater. Interfaces 2014, 6, 12153-12167. [CrossRef]

8. Naveenraj, S.; Lee, G.-J.; Anandan, S.; Wu, J.J. Nanosized tantala based materials—Synthesis and applications. Mater. Res. Bull. 2015, 67, 20-46. [CrossRef]

9. Nikishina, E.E.; Lebedeva, E.N.; Drobot, D.V. Niobium- and tantalum-containing oxide materials: Synthesis, properties, and application. Inorg. Mater. 2012, 48, 1243-1260. [CrossRef]

10. Wang, T.; Liu, S.; Li, H.; Li, C.; Luo, Z.; Gong, J. Transparent $\mathrm{Ta}_{2} \mathrm{O}_{5}$ Protective Layer for Stable Silicon Photocathode under Full Solar Spectrum. Ind. Eng. Chem. Res. 2019, 58, 5510-5515. [CrossRef]

11. Gao, W.; Zhang, Z.; Dou, M.; Wang, F. Highly Dispersed and Crystalline $\mathrm{Ta}_{2} \mathrm{O}_{5}$ Anchored Pt Electrocatalyst with Improved Activity and Durability Toward Oxygen Reduction: Promotion by Atomic-Scale Pt-Ta $2 \mathrm{O}_{5}$ Interactions. ACS Catal. 2019, 9, 3278-3288. [CrossRef]

12. Fu, W.; Zhuang, P.; Chee, M.O.; Dong, P.; Ye, M.; Shen, J. Oxygen Vacancies in $\mathrm{Ta}_{2} \mathrm{O}_{5}$ Nanorods for Highly Efficient Electrocatalytic N2 Reduction to NH3 under Ambient Conditions. ACS Sustain. Chem. Eng. 2019, 7, 9622-9628. [CrossRef]

13. Dang, H.X.; Hahn, N.T.; Park, H.S.; Bard, A.J.; Mullins, C.B. Nanostructured $\mathrm{Ta}_{3} \mathrm{~N}_{5}$ Films as Visible-Light Active Photoanodes for Water Oxidation. J. Phys. Chem. C 2012, 116, 19225-19232. [CrossRef]

14. Ho, C.-T.; Low, K.-B.; Jash, P.; Shen, H.; Snee, P.T.; Meyer, R.J. Formation of Sol-Gel-Derived TaO $\mathrm{T}_{\mathrm{x}}$ Photocatalysts. Chem. Mater. 2011, 23, 4721-4725. [CrossRef]

15. Harb, M.; Sautet, P.; Nurlaela, E.; Raybaud, P.; Cavallo, L.; Domen, K.; Basset, J.M.; Takanabe, K. Tuning the properties of visible-light-responsive tantalum (oxy)nitride photocatalysts by non-stoichiometric compositions: A first-principles viewpoint. Phys. Chem. Chem. Phys. 2014, 16, 20548-20560. [CrossRef]

16. Oi-Uchisawa, J.; Obuchi, A.; Enomoto, R.; Liu, S.; Nanba, T.; Kushiyama, S. Catalytic performance of Pt supported on various metal oxides in the oxidation of carbon black. Appl. Catal. B Environ. 2000, 26, 17-24. [CrossRef]

17. Gan, J.; Lu, X.; Tong, Y. Towards highly efficient photoanodes: Boosting sunlight-driven semiconductor nanomaterials for water oxidation. Nanoscale 2014, 6, 7142. [CrossRef]

18. Vo, V.; Van Kim, N.; Nga, N.T.; Trung, N.T.; Van Hanh, P.; Hoang, L.H.; Kim, S.J. Preparation of g- $\mathrm{C}_{3} \mathrm{~N}_{4} / \mathrm{Ta}_{2} \mathrm{O}_{5}$ Composites with Enhanced Visible-Light Photocatalytic Activity. J. Electron. Mater. 2016, 45, $2334-2340$. [CrossRef] 
19. Ghugal, S.G.; Umare, S.S.; Sasikala, R. Photocatalytic mineralization of anionic dyes using bismuth doped CdS- $\mathrm{Ta}_{2} \mathrm{O}_{5}$ composite. RSC Adv. 2015, 5, 63393-63400. [CrossRef]

20. Tao, C.; Xu, L.; Guan, J. Well-dispersed mesoporous $\mathrm{Ta}_{2} \mathrm{O}_{5}$ submicrospheres: Enhanced photocatalytic activity by tuning heating rate at calcination. Chem. Eng. J. 2013, 229, 371-377. [CrossRef]

21. Liu, X.; Zhao, L.; Domen, K.; Takanabe, K. Photocatalytic hydrogen production using visible-light-responsive Ta 3N5 photocatalyst supported on monodisperse spherical $\mathrm{SiO}_{2}$ particulates. Mater. Res. Bull. 2014, 49, 58-65. [CrossRef]

22. Takahara, Y.; Kondo, J.N.; Takata, T.; Lu, D.; Domen, K. Mesoporous Tantalum Oxide. 1. Characterization and Photocatalytic Activity for the Overall Water Decomposition. Chem. Mater. 2001, 13, 1194-1199. [CrossRef]

23. Grewe, T.; Tüysüz, H. Alkali metals incorporated ordered mesoporous tantalum oxide with enhanced photocatalytic activity for water splitting. J. Mater. Chem. A 2016, 4, 3007-3017. [CrossRef]

24. Xu, L.; Guan, J.; Shi, W. Enhanced Interfacial Charge Transfer and Visible Photocatalytic Activity for Hydrogen Evolution from a $\mathrm{Ta}_{2} \mathrm{O}_{5}$-based Mesoporous Composite by the Incorporation of Quantum-Sized CdS. ChemCatChem 2012, 4, 1353-1359. [CrossRef]

25. Gonçalves, R.V.; Migowski, P.; Wender, H.; Eberhardt, D.; Weibel, D.E.; Sonaglio, F.C.; Zapata, M.J.; Dupont, J.; Feil, A.F.; Teixeira, S.R. $\mathrm{Ta}_{2} \mathrm{O}_{5}$ Nanotubes Obtained by Anodization: Effect of Thermal Treatment on the Photocatalytic Activity for Hydrogen Production. J. Phys. Chem. C 2012, 116, 14022-14030. [CrossRef]

26. Luo, Y.; Liu, X.; Tang, X.; Luo, Y.; Zeng, Q.; Deng, X.; Ding, S.; Sun, Y. Gold nanoparticles embedded in $\mathrm{Ta}_{2} \mathrm{O}_{5} / \mathrm{Ta}_{3} \mathrm{~N}_{5}$ as active visible-light plasmonic photocatalysts for solar hydrogen evolution. J. Mater. Chem. A 2014, 2, 14927-14939. [CrossRef]

27. Wang, Y.; Ma, W.; Chen, C.; Hu, X.; Zhao, J.; Yu, J.C. Fe ${ }^{3+} / \mathrm{Fe}^{2+}$ cycling promoted by $\mathrm{Ta}_{3} \mathrm{~N}_{5}$ under visible irradiation in Fenton degradation of organic pollutants. Appl. Catal. B Environ. 2007, 75, 256-263. [CrossRef]

28. Rooke, J.C.; Barakat, T.; Brunet, J.; Li, Y.; Finol, M.F.; Lamonier, J.F.; Giraudon, J.M.; Cousin, R.; Siffert, S.; $\mathrm{Su}, \mathrm{B} . \mathrm{L}$. Hierarchically nanostructured porous group $\mathrm{Vb}$ metal oxides from alkoxide precursors and their role in the catalytic remediation of VOCs. Appl. Catal. B Environ. 2015, 162, 300-309. [CrossRef]

29. Sun, H.; Liu, S.; Liu, S.; Wang, S. A comparative study of reduced graphene oxide modified $\mathrm{TiO}_{2}, \mathrm{ZnO}$ and Ta2O5 in visible light photocatalytic/photochemical oxidation of methylene blue. Appl. Catal. B Environ. 2014, 146, 162-168. [CrossRef]

30. Ma, S.S.K.; Maeda, K.; Hisatomi, T.; Tabata, M.; Kudo, A.; Domen, K. A Redox-Mediator-Free Solar-Driven Z-Scheme Water-Splitting System Consisting of Modified $\mathrm{Ta}_{3} \mathrm{~N}_{5}$ as an Oxygen-Evolution Photocatalyst. Chem. A. Eur. J. 2013, 19, 7480-7486. [CrossRef]

31. Ma, S.S.K.; Hisatomi, T.; Maeda, K.; Moriya, Y.; Domen, K. Enhanced Water Oxidation on $\mathrm{Ta}_{3} \mathrm{~N}_{5}$ Photocatalysts by Modification with Alkaline Metal Salts. J. Am. Chem. Soc. 2012, 134, 19993-19996. [CrossRef]

32. Higashi, T.; Nishiyama, H.; Suzuki, Y.; Sasaki, Y.; Hisatomi, T.; Katayama, M.; Minegishi, T.; Seki, K.; Yamada, T.; Domen, K. Transparent $\mathrm{Ta}_{3} \mathrm{~N}_{5}$ Photoanodes for Efficient Oxygen Evolution toward the Development of Tandem Cells. Angew. Chem. Int. Ed. 2019, 58, 2300-2304. [CrossRef] [PubMed]

33. Sato, S.; Morikawa, T.; Saeki, S.; Kajino, T.; Motohiro, T. Visible-Light-Induced Selective $\mathrm{CO}_{2}$ Reduction Utilizing a Ruthenium Complex Electrocatalyst Linked to a p-Type Nitrogen-Doped $\mathrm{Ta}_{2} \mathrm{O}_{5}$ Semiconductor. Angew. Chem. Int. Ed. 2010, 49, 5101-5105. [CrossRef]

34. Huang, J.; Ma, R.; Ebina, Y.; Fukuda, K.; Takada, K.; Sasaki, T. Layer-by-Layer Assembly of $\mathrm{TaO}_{3}$ Nanosheet/Polycation Composite Nanostructures: Multilayer Film, Hollow Sphere, and Its Photocatalytic Activity for Hydrogen Evolution. Chem. Mater. 2010, 22, 2582-2587. [CrossRef]

35. Li, J.; Dai, W.; Wu, G.; Guan, N.; Li, L. Fabrication of $\mathrm{Ta}_{2} \mathrm{O}_{5}$ films on tantalum substrate for efficient photocatalysis. Catal. Commun. 2015, 65, 24-29. [CrossRef]

36. Yokomichi, Y.; Nakayama, T.; Okada, O.; Yokoi, Y.; Takahashi, I.; Uchida, H.; Ishikawa, H.; Yamaguchi, R.; Matsui, H.; Yamabe, T. CATALYSIS TODAY i Fundamental study on the NO $x$ direct decomposition catalysts. Catal. Today 1996, 29, 155-160. [CrossRef]

37. Subramanian, V.; Kamat, P.V.; Wolf, E.E. Mass-transfer and kinetic studies during the photocatalytic degradation of an azo dye on optically transparent electrode thin film. Ind. Eng. Chem. Res. 2003, 42, 2131-2138. [CrossRef]

38. Zhu, Y.; Yu, F.; Man, Y.; Tian, Q.; He, Y.; Wu, N. Preparation and performances of nanosized $\mathrm{Ta}_{2} \mathrm{O}_{5} \mathrm{Powder}$ photocatalyst. J. Solid State Chem. 2005, 178, 224-229. [CrossRef] 
39. Murase, T.; Irie, H.; Hashimoto, K. Visible light sensitive photocatalysts, nitrogen-doped $\mathrm{Ta}_{2} \mathrm{O}_{5}$ powders. J. Phys. Chem. B 2004, 108, 15803-15807. [CrossRef]

40. Ndiege, N.; Wilhoite, T.; Subramanian, V.; Shannon, M.A.; Masel, R.I. Sol-gel synthesis of thick $\mathrm{Ta}_{2} \mathrm{O}_{5}$ films. Chem. Mater. 2007, 19, 3155-3161. [CrossRef]

41. Wang, S.; Guan, Y.; Wang, L.; Zhao, W.; He, H.; Xiao, J.; Yang, S.; Sun, C. Fabrication of a novel bifunctional material of $\mathrm{BiOI} / \mathrm{Ag}_{3} \mathrm{VO}_{4}$ with high adsorption-photocatalysis for efficient treatment of dye wastewater. Appl. Catal. B Environ. 2015, 168, 448-457. [CrossRef]

42. Jones, D.R.; Gomez, V.; Bear, J.C.; Rome, B.; Mazzali, F.; McGettrick, J.D.; Lewis, A.R.; Margadonna, S.; Al-Masry, W.A.; Dunnill, C.W. Active removal of waste dye pollutants using $\mathrm{Ta}_{3} \mathrm{~N}_{5} / \mathrm{W}_{18} \mathrm{O}_{49}$ nanocomposite fibres. Sci. Rep. 2017, 7, 1-16. [CrossRef] [PubMed]

43. Garza-Tovar, L.L.; Torres-Martínez, L.M.; Rodríguez, D.B.; Gómez, R.; del Angel, G. Photocatalytic degradation of methylene blue on $\mathrm{Bi}_{2} \mathrm{MNbO}_{7}(\mathrm{M}=\mathrm{Al}, \mathrm{Fe}, \mathrm{In}, \mathrm{Sm})$ sol-gel catalysts. J. Mol. Catal. A Chem. 2006, 247, 283-290. [CrossRef]

44. Houas, A.; Lachheb, H.; Ksibi, M.; Elaloui, E.; Guillard, C.; Herrmann, J.-M. Photocatalytic degradation pathway of methylene blue in water. Appl. Catal. B Environ. 2001, 31, 145-157. [CrossRef]

45. Kim, E.S.; Nishimura, N.; Magesh, G.; Kim, J.Y.; Jang, J.W.; Jun, H.; Kubota, J.; Domen, K.; Lee, J.S. Fabrication of $\mathrm{CaFe}_{2} \mathrm{O}_{4} / \mathrm{TaON}$ heterojunction photoanode for photoelectrochemical water oxidation. J. Am. Chem. Soc. 2013, 135, 5375-5383. [CrossRef] [PubMed]

46. Molla, A.; Sahu, M.; Hussain, S. Under dark and visible light: Fast degradation of methylene blue in the presence of Ag-In-Ni-S nanocomposites. J. Mater. Chem. A 2015, 3, 15616-15625. [CrossRef]

47. Smith, Y.R.; Kar, A.; Subramanian, V. Investigation of physicochemical parameters that influence photocatalytic degradation of methyl orange over $\mathrm{TIO}_{2}$ nanotubes. Ind. Eng. Chem. Res. 2009, 48, 10268-10276. [CrossRef]

48. Sohn, Y.S.; Smith, Y.R.; Misra, M.; Ravi, V. Subramanian, Electrochemically assisted photocatalytic degradation of methyl orange using anodized titanium dioxide nanotubes. Appl. Catal. B Environ. 2008, 84, 372-378. [CrossRef]

49. Mukherjee, B.; Wilson, W.; Ravi, V. Subramanian, $\mathrm{TiO}_{2}$ nanotube (T_NT) surface treatment revisited: Implications of $\mathrm{ZnO}, \mathrm{TiCl}_{4}$, and $\mathrm{H}_{2} \mathrm{O}_{2}$ treatment on the photoelectrochemical properties of T_NT and T_NT-CdSe. Nanoscale 2013, 5, 269-274. [CrossRef]

50. Mukherjee, B.; Peterson, A.; Subramanian, V. 1D CdS/PbS heterostructured nanowire synthesis using cation exchange. Chem. Commun. 2012, 48, 2415. [CrossRef]

51. Gupta, S.; de Leon, L.; Ravi, V. Subramanian, Mn-modified $\mathrm{Bi}_{2} \mathrm{Ti}_{2} \mathrm{O}_{7}$ photocatalysts: Bandgap engineered multifunctional photocatalysts for hydrogen generation. Phys. Chem. Chem. Phys. 2014, 16, 12719-12727. [CrossRef] [PubMed]

52. Ismail, A.A.; Faisal, M.; Harraz, F.A.; Al-Hajry, A.; Al-Sehemi, A.G. Synthesis of mesoporous sulfur-doped Ta2O5nanocomposites and their photocatalytic activities. J. Colloid Interface Sci. 2016, 471, 145-154. [CrossRef] [PubMed]

53. Guo, G.; Huang, J. Preparation of mesoporous tantalum oxide and its enhanced photocatalytic activity. Mater. Lett. 2011, 65, 64-66. [CrossRef]

54. Hsieh, J.H.; Li, C.; Liang, H.C. Structures and photocatalytic behavior of tantalum-oxynitride thin films. Thin Solid Films 2011, 519, 4699-4704. [CrossRef]

55. Peng, Y.-J.; Lee, S.-Y.; Chang, K.-S. Facile Fabrication of a Photocatalyst of $\mathrm{Ta}_{4} \mathrm{~N}_{5}$ Nanocolumn Arrays by Using Reactive Sputtering. J. Electrochem. Soc. 2015, 162, H371-H375. [CrossRef]

56. Liu, S.; Sun, H.; Liu, S.; Wang, S. Graphene facilitated visible light photodegradation of methylene blue over titanium dioxide photocatalysts. Chem. Eng. J. 2013, 214, 298-303. [CrossRef]

57. Jiang, F.; Yan, T.; Chen, H.; Sun, A.; Xu, C.; Wang, X. A g- $\mathrm{C}_{3} \mathrm{~N}_{4}-\mathrm{CdS}$ composite catalyst with high visible-light-driven catalytic activity and photostability for methylene blue degradation. Appl. Surf. Sci. 2014, 295, 164-172. [CrossRef]

58. Zhu, G.; Lin, T.; Cui, H.; Zhao, W.; Zhang, H.; Huang, F. Gray Ta $\mathrm{O}_{5}$ Nanowires with Greatly Enhanced Photocatalytic Performance. ACS Appl. Mater. Interfaces 2016, 8, 122-127. [CrossRef]

59. Ji, K.; Deng, J.; Zang, H.; Han, J.; Arandiyan, H.; Dai, H. Fabrication and high photocatalytic performance of noble metal nanoparticles supported on $3 \mathrm{DOM} \mathrm{InVO}_{4}-\mathrm{BiVO}_{4}$ for the visible-light-driven degradation of rhodamine B and methylene blue. Appl. Catal. B Environ. 2015, 165, 285-295. [CrossRef] 
60. Umrao, S.; Abraham, S.; Theil, F.; Pandey, S.; Ciobota, V.; Shukla, P.K.; Rupp, C.J.; Chakraborty, S.; Ahuja, R.; Popp, J.; et al. A possible mechanism for the emergence of an additional band gap due to a Ti-O-C bond in the $\mathrm{TiO}_{2}$-graphene hybrid system for enhanced photodegradation of methylene blue under visible light. RSC Adv. 2014, 4, 59890-59901. [CrossRef]

61. Chun, W.J.; Ishikawa, A.; Fujisawa, H.; Takata, T.; Kondo, J.N.; Hara, M.; Kawai, M.; Matsumoto, Y.; Domen, K. Conduction and valence band positions of $\mathrm{Ta}_{2} \mathrm{O}_{5}, \mathrm{TaON}$, and $\mathrm{Ta}_{3} \mathrm{~N}_{5}$ by UPS and electrochemical methods. J. Phys. Chem. B 2003, 107, 1798-1803. [CrossRef]

62. Cui, Z.; Jiang, H. Theoretical Investigation of $\mathrm{Ta}_{2} \mathrm{O}_{5}, \mathrm{TaON}$, and $\mathrm{Ta}_{3} \mathrm{~N}_{5}$ : Electronic Band Structures and Absolute Band Edges. J. Phys. Chem. C 2017, 121, 3241-3251. [CrossRef]

63. Khanal, V.; Irani, R.; Fiechter, S.; Abdi, F.F.; Subramanian, V.R. The Photoelectrochemical and Photocatalytic Properties of Tantalum Oxide and Tantalum Nitride. J. Electrochem. Soc. 2019, 166, 1-7. [CrossRef]

64. Subramanian, V.; Wolf, E.; Kamat, P.V. Semiconductor-Metal Composite Nanostructures. To What Extent Do Metal Nanoparticles Improve the Photocatalytic Activity of $\mathrm{TiO}_{2}$ Films? J. Phys. Chem. B 2001, 105, 11439-11446. [CrossRef]

65. Phulé, P.P. Sol-gel synthesis of ferroelectric lithium tantalate ceramics: FTIR investigation of the molecular modification of tantalum ethoxide. J. Mater. Res. 1993, 8, 334-338. [CrossRef]

66. Wang, Z.; Hou, J.; Jiao, S.; Huang, K.; Zhu, H. In situ chemical reduction of the $\mathrm{Ta}_{3} \mathrm{~N}_{5}$ quantum dots coupled TaON hollow spheres heterojunction photocatalyst for water oxidation. J. Mater. Chem. 2012, 22, 21972. [CrossRef]

67. Stampfl, C.; Freeman, A.J. Stable and metastable structures of the multiphase tantalum nitride system. Phys. Rev. B 2005, 71, 024111. [CrossRef]

68. Ishikawa, A.; Takata, T.; Kondo, J.N.; Hara, M.; Domen, K. Electrochemical behavior of thin $\mathrm{Ta}_{3} \mathrm{~N}_{5}$ semiconductor film. J. Phys. Chem. B 2004, 108, 11049-11053. [CrossRef]

69. Brauer, G.; Weidlein, J.R. Synthesis and Properties of Tantalum Oxide Nitride, TaON. Angew. Chem. Int. Ed. 1965, 4, 875. [CrossRef]

70. Orhan, E.; Tessier, F.; Marchand, R. Synthesis and energetics of yellow TaON. Solid State Sci. 2002, 4, 1071-1076. [CrossRef]

71. De Respinis, M.; Fravventura, M.; Abdi, F.F.; Schreuders, H.; Savenije, T.J.; Smith, W.A.; Dam, B.; van de Krol, R. Oxynitrogenography: Controlled Synthesis of Single-Phase Tantalum Oxynitride Photoabsorbers. Chem. Mater. 2015, 27, 7091-7099. [CrossRef]

72. Ojha, M.; Dhiman, A.K. Problem, Failure and Safety Analysis of Ammonia Plant: A Review. Int. Rev. Chem. Eng. 2010, 2, 631-646.

73. Gao, Q.; Giordano, C.; Antonietti, M. Controlled synthesis of tantalum oxynitride and nitride nanoparticles. Small 2011, 7, 3334-3340. [CrossRef] [PubMed]

74. Sasaki, Y.; Tokuyasu, Z.; Ono, Y.; Iwasaki, M.; Ito, S. Synthetic conditions and color characteristics of tantalum oxynitride prepared via liquid- $\mathrm{NH}_{3}$ process. Adv. Mater. Sci. Eng. 2009, 2009, 2-6. [CrossRef] 